\title{
Residence-related factors and psychological distress among evacuees after the Fukushima Daiichi nuclear power plant accident: a cross-sectional study
}

\author{
Naoko Horikoshi ${ }^{1 *}$ (D, Hajime Iwasa ${ }^{1,2}$, Norito Kawakami ${ }^{3}$, Yuriko Suzuki ${ }^{4}$ and Seiji Yasumura ${ }^{1}$
}

\begin{abstract}
Background: Relocation following a disaster can impact the psychological well-being of evacuees. This study investigated the associations between residence-related factors and psychological distress among evacuees living in temporary housing after the Fukushima Daiichi Nuclear Power Plant accident.

Methods: Data from 525 participants living in temporary housing were collected. Associations between residence-related factors (frequent relocation, dissatisfaction with the residence, and plan to move to permanent housing) and psychological distress were measured. The psychological distress of evacuees was measured using the Japanese version of the 6-item Kessler scale (K6). We used a cut-off score of five to identify cases with psychological distress, the basis of Kessler's 6 items for psychological distress.

Results: Multivariate logistic regression analysis $(n=418)$ showed that frequent relocation $(\mathrm{OR}=2.05,95 \%$ Cl: 1.14-3.66, $p=0.016)$ and dissatisfaction with the residence $(\mathrm{OR}=2.48,95 \% \mathrm{Cl}: 1.60-3.83, p<0.001)$ was significantly associated with psychological distress. After stratifying by gender, dissatisfaction with the residence was associated with psychological distress, and a plan to move to permanent housing was significantly associated with psychological distress in women $(\mathrm{OR}=1.93,95 \% \mathrm{Cl}: 1.03-3.63, p=0.041)$.

Conclusions: Frequent relocation and dissatisfaction with the residence were associated with psychological distress among evacuees following the Fukushima nuclear disaster. Evacuees should be provided with comfortable living spaces, and steps should be taken to reduce repeated relocation of evacuees. Thus, particular attention should be paid to women with a plan to move to permanent housing within this context.
\end{abstract}

Keywords: Psychological distress, Community mental health, Disaster, Relocation, Residence

\section{Background}

The Great East Japan Earthquake and tsunami that occurred on March 11, 2011, damaged the Fukushima Daiichi Nuclear Power Plant, leading to the Fukushima nuclear disaster. The impact of the earthquake and the subsequent evacuation of residents into unfamiliar environments due to the radiation hazard are expected to cause psychological distress $[1,2]$. According to

\footnotetext{
* Correspondence: copepe@fmu.ac.jp

${ }^{1}$ Department of Public Health, Fukushima Medical University School of Medicine, 1 Hikarigaoka, Fukushima City, Fukushima 960-1295, Japan

Full list of author information is available at the end of the article
}

previous studies, a major long-term health issue following the Chernobyl nuclear accident is psychological distress [3].

Disaster-related relocation affects the psychological well-being of evacuees [4, 5]. Erikson [6], through research with those affected by the Buffalo Creek flood, has reported an effect on psychological distress that was likely caused by the loss of social resources (such as the familiar places and human relationships). Previous studies report many instances of psychological issues following the forced evacuation of homes, due to natural or man-made disasters (such as hurricanes $[7,8]$, earthquakes [9], terrorist attacks [10], and explosion 
[11]. Uscher-Pones [12] reported that healthcare disruption, social network change, living condition change, psychological stressors, and individual vulnerability are all associated with heath status within the conceptual framework of the health effects of postdisaster relocation.

Since evacuees following the Fukushima nuclear disaster were suddenly forced into long-term evacuation, their stress is likely considerable. Many evacuees continue to feel anxiety regarding their health, and report mental issues caused by the evacuation [13, 14]. Therefore, the originality of this study is best described by the following three points. First, this study is focused on the evacuees of a complex disaster (i.e. earthquake, tsunami, and nuclear power plant accident). In addition to the natural elements, the nuclear disaster described in the current study was unexpected, unprecedented, and likely the worst nuclear accident in history $[1,2]$. Within the framework of this unique occurrence, we aimed to investigate an association between residence-related factors and psychological distress in such complex disasters.

Second, residence-related and psychological problems among evacuees after disasters have been found as well, such as being forced to leave home and be relocated $[7,8]$, dissatisfaction with the relocation residence [15], and housing damage [16, 17]. However, we feel that the number of those that have been relocated, and plan to move to permanent housing within the relocated area in the future, have not been given adequate consideration in previous studies.

Finally, previous research has shown that sex is one of the factors that affects mental health in the relocation after disaster $[5,18]$, with women exhibiting diminished resiliency. In addition, youth has been stated as having a high impact on psychological problems after disaster, as a result of increased responsibility, such as home rebuilding [19]. Given this information, the current study focuses on specific differences in age and gender groups.

Furthermore, as women [5, 18, 20] and non-elderly $[16,19]$ are reportedly particularly susceptible and vulnerable to psychological distress, it is also important to clarify any associations between psychological distress and age or gender group.

Currently, the government has begun to build permanent housing, such as disaster-related public housing, in order to ensure a stable living environment for evacuees. Confirmation of any relationship between residencerelated factors and psychological distress could contribute to assessing the psychological well-being of evacuees who started to move to such new environments. In addition, recognition of the factors that affect evacuees after a disaster could assist in developing precautionary measures to reduce psychological distress following future disasters.
Therefore, this study addressed frequent relocation, dissatisfaction with the residence, and plan to move to permanent housing as residence-related factors that might impact psychological well-being. This would be performed by clarifying associations between residencerelated factors and psychological distress among evacuees living in temporary housing after the Fukushima nuclear disaster.

\section{Methods \\ Participants}

This study was conducted from October 2013 to January 2014. Subjects were recruited from five temporary housing complexes, located in two municipalities, following the Fukushima nuclear accident. Housing complex registration lists, which included names, head of household, number in family, and ages, were used to initiate contact. Of 673 households, 535 households were successfully contacted. From these households, we selected those who had been living in Fukushima Prefecture before the Fukushima nuclear disaster. These consisted of 922 individuals aged 20 years or older, among whom 525 individuals (response rate: 56.9\%) agreed to participate in the study (see Fig. 1).

\section{Outcome measures}

The psychological distress of evacuees was measured using the Japanese version [21] of the 6-item Kessler scale (K6) [22]. The K6 is a self-administered questionnaire consisting of six questions that evaluate depressive moods and anxiety over the preceding 4 weeks on a 5 -point scale, ranging from 0 to 4 . The total score is an equally weighted sum of the six items, with possible scores ranging from 0 to 24 . In this study, we used a cut-off score of five to identify cases with psychological distress, which has been determined as an appropriate threshold for identifying the Diagnostic and Statistical Manual of Mental Disorders, fourth edition (DSM-IV) mood and anxiety disorders in previous studies of community populations in Japan [23, 24].

\section{Data collection}

Data for residence-related factors were as follows: 1) frequent relocation (4 or more times), 2) dissatisfaction with the residence, and 3) plan to move to permanent housing. Dissatisfaction with the residence was scored from 1 (very satisfied) to 5 (very dissatisfied).

Demographic information was collected via selfadministered questionnaire, and included respondent age, gender, employment status, financial circumstances, family size, family members, housing damage, loss of close relatives, and presence/absence of psychiatric disorder. Age was classified into two groups: 20-64 years and 65 years or older. Employment status was classified 


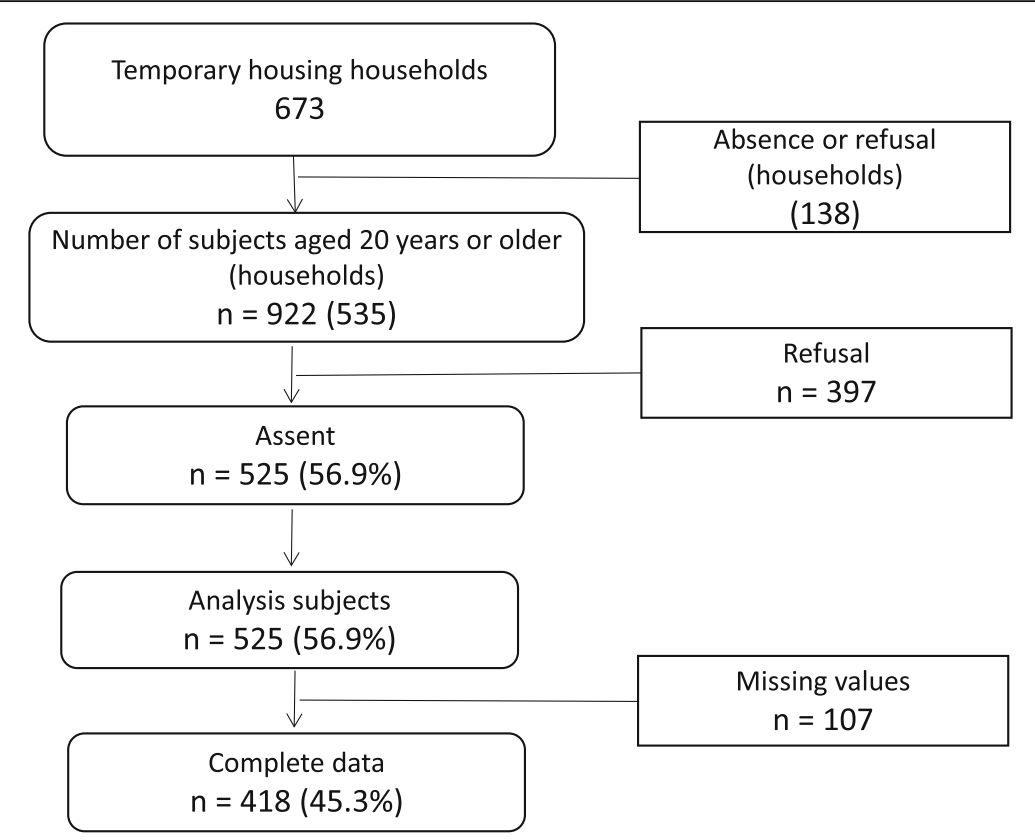

Fig. 1 Selection of participants

into three groups: unemployed (which included homemakers), employed, and retired. Financial circumstances were divided into two groups, based on a five-point scale: bad (very poor/poor) and good (average/good/very good). Family members were classified into three groups: living alone, spouses, and other (including family structures such as two-generation households, i.e. elderly parents living with their children). Housing damage was classified into two groups: yes (damage) and no (no damage).

\section{Statistical analysis}

Univariate analysis was used to analyze data from 525 people who completed the self-administered questionnaire and took part in a face-to-face interview. Multivariate logistic regression analysis was used to analyze data from 418 participants with a complete set of data. Also, employment status (unemployed and retired/ employed) and family members (living alone and spouses/other) were changed to binary from three values for purposes of analysis.

To examine the association between residence-related factors and psychological distress, we used chi-square tests and Student's t-tests to address categorical and continuous variables, respectively. For statistical comparisons, chi-square tests followed by residual analysis were applied to employment status and marital status. Subsequently, we used a multivariate logistic regression analysis to assess associations between psychological distress and residence-related factors (frequent relocation, dissatisfaction with the residence, and plans to move to permanent housing). We then repeated the above analysis while stratifying by age and gender groups to examine the interaction. The score was expressed as mean and standard deviation (SD), and $p<0.05$ was regarded to indicate statistical significance. All statistical procedures were performed using SPSS for Windows (version 21; IBM, Chicago, USA).

\section{Results}

The characteristics of the study population by age (younger people: $20-64$ years old; older people: $\geq 65$ years old) and gender groups are shown in Table 1.

The sample included 325 women (61.9\%), with an average age of 66.2 years $(\mathrm{SD}=15.1$, range $=21-91$ years). The majority of participants were unemployed $(n=306,59.8 \%)$, and reported good financial circumstances $(n=425,83.5 \%)$. The ratio of employment status differed significantly by age group $(p<0.001)$ and gender $(p<0.001)$; marital status differed significantly $(p<0.001)$ by age group. Family size after the disaster was significantly lower for older people (mean: 1.9 people, $\mathrm{SD}=0.9)$ compared to for younger people (mean: 2.5 people, $\mathrm{SD}=1.4 ; \quad p<0.001)$, and family size was reduced significantly after the disaster (mean 2.1 people, $\mathrm{SD}=1.2$ ) compared to before the disaster (mean 3.7 people, $\mathrm{SD}=2.2 ; p<0.001$ ). In addition, the percentage of those who owned houses before the disaster was $90.6 \%$.

The primary residence-related factor was frequent relocation $(n=378,76.1 \%)$; the mean number of relocations was $4.6(\mathrm{SD}=1.7)$. Associations between the number of relocation and psychological distress were as follows: $\geq 3$ relocations, $p=0.047 ; \geq 4$ relocations, $p=0.024$; and $\geq 5$ 
Table 1 Characteristics of the study population by age and gender

\begin{tabular}{|c|c|c|c|c|c|c|}
\hline Variable & & All participants & $<65$ & $\geq 65$ & Men & Women \\
\hline \multirow[t]{3}{*}{ Age } & Mean (SD) & $66.2(15.1)$ & --- & --- & $66.0(14.0)$ & $66.3(15.8)$ \\
\hline & $<65$ & $199(37.9)$ & --- & --- & $75(37.5)$ & $124(38.2)$ \\
\hline & $\geq 65$ & $326(62.1)$ & --- & --- & $125(62.5)$ & $201(61.8)$ \\
\hline \multirow[t]{2}{*}{ Gender } & Men & $200(38.1)$ & $75(37.7)$ & $125(38.3)$ & -- & --- \\
\hline & Women & $325(61.9)$ & $124(62.3)$ & $201(61.7)$ & --- & --- \\
\hline \multirow[t]{3}{*}{ Employment status $^{\mathrm{a}}$} & Unemployed & $306(59.8)$ & 107 (54.9) & $199(62.8)^{* * *}$ & $78(40.0)$ & $228(71.9)^{* * *}$ \\
\hline & Retired & $111(21.7)$ & $15(7.7)$ & $96(30.3)$ & $69(35.4)$ & $42(13.2)$ \\
\hline & Employed & 95 (18.6) & $73(37.4)$ & $22(6.9)$ & $48(24.6)$ & $47(14.8)$ \\
\hline \multirow[t]{2}{*}{ Financial circumstances } & Bad & $84(16.5)$ & $39(20.2)$ & $45(14.2)$ & $39(20.2)$ & $45(14.2)$ \\
\hline & Good & $425(83.5)$ & $154(79.8)$ & $271(85.8)$ & $154(79.8)$ & $271(85.8)$ \\
\hline \multirow[t]{2}{*}{ Family size (mean (SD)) } & Before disaster & $3.7(2.2)$ & $3.7(2.2)$ & $3.6(2.2)$ & $3.5(2.2)$ & $3.8(2.2)$ \\
\hline & After disaster & $2.1(1.2)$ & $2.5(1.4)$ & $1.9(0.9)^{* * *}$ & $2.0(1.1)$ & $2.1(1.2)$ \\
\hline \multirow[t]{3}{*}{ Family members $^{\mathrm{b}}$} & Lliving alone & $150(29.0)$ & $43(21.7)$ & $107(33.4)^{* * *}$ & $59(29.9)$ & $91(28.3)$ \\
\hline & Spouses & $197(38.0)$ & $56(28.3)$ & $141(44.1)$ & $82(41.6)$ & $115(35.8)$ \\
\hline & Other & $171(33.0)$ & $99(50.0)$ & $72(22.5)$ & $56(28.4)$ & $115(35.8)$ \\
\hline \multirow[t]{2}{*}{ Housing damage } & No & $174(34.6)$ & $76(39.2)$ & $98(31.7)$ & $61(31.6)$ & $113(36.5)$ \\
\hline & Yes & $329(65.4)$ & $118(60.8)$ & $211(68.3)$ & $132(68.4)$ & $197(63.5)$ \\
\hline \multirow[t]{2}{*}{ Loss of close relatives } & None & $308(61.2)$ & $122(62.9)$ & $186(60.2)$ & $118(61.1)$ & $190(61.3)$ \\
\hline & $\geq 1$ & $195(38.8)$ & $72(37.1)$ & $123(39.8)$ & 75 (38.9) & $120(38.7)$ \\
\hline \multirow[t]{2}{*}{ Psychiatric disorder } & No & 393 (93.6) & $145(91.2)$ & $248(95.0)$ & $153(95.0)$ & $240(92.7)$ \\
\hline & Yes & $27(6.4)$ & $14(8.8)$ & $13(5.0)$ & $8(5.0)$ & $19(7.3)$ \\
\hline \multirow[t]{3}{*}{ Frequent relocation } & Mean(SD) & $4.6(1.7)$ & $4.6(1.6)$ & $4.7(1.7)$ & $4.6(1.6)$ & $4.7(1.7)$ \\
\hline & $<4$ & $119(23.9)$ & $50(26.0)$ & $69(22.6)$ & $48(25.1)$ & $71(23.2)$ \\
\hline & $\geq 4$ & $378(76.1)$ & $142(74.0)$ & $236(77.4)$ & $143(74.9)$ & $235(76.8)$ \\
\hline \multirow{2}{*}{$\begin{array}{l}\text { Dissatisfaction with the } \\
\text { residence }\end{array}$} & No & $268(53.7)$ & $108(56.0)$ & $160(52.3)$ & $103(53.6)$ & $165(53.7)$ \\
\hline & Yes & $231(46.3)$ & $85(44.0)$ & $146(47.7)$ & 89 (46.4) & $142(46.3)$ \\
\hline \multirow{2}{*}{$\begin{array}{l}\text { Plan to move to } \\
\text { permanent housing }\end{array}$} & No & $334(72.1)$ & $119(67.6)$ & $215(74.9)$ & 130 (72.6) & $204(71.8)$ \\
\hline & Yes & $129(27.9)$ & $57(32.4)$ & $72(25.1)$ & 49 (27.4) & $80(28.2)$ \\
\hline \multirow[t]{3}{*}{ K6 } & Mean(SD) & $3.6(4.5)$ & $3.3(4.3)$ & $3.7(4.7)$ & $3.0(4.0)$ & $3.9(4.8)^{*}$ \\
\hline & $<5$ & $316(66.2)$ & $122(67.8)$ & $194(65.3)$ & $122(68.2)$ & $194(65.1)$ \\
\hline & $\geq 5$ & 161 (33.8) & $58(32.2)$ & $103(34.7)$ & 57 (31.8) & $104(34.9)$ \\
\hline
\end{tabular}

Cells show frequencies, with percentages in parentheses. Chi-square tests, Student's t-test, and Pearson product-moment correlation coefficients were used for analyses. * $p<0.05 * * * 00.001$

Results of statistical analysis using residual analysis

aln those aged below 65 years, those who were retired accounted for less than the expected value, while those who were employed comprised more than the expected value. On the other hand, among those aged 65 or older, those who were retired formed more than the expected value, while those who were employed formed less than the expected value. In the case of men, those who were unemployed comprised less than the expected value, and those who were retired or employed formed larger than the expected values. On the other hand, in the case of women, those who were unemployed formed larger than the expected value, and those who were retired or employed formed less than the expected value

${ }^{b}$ In those below 65 years, those who were living alone or spouses formed less than the expected values, while those who chose "other" comprised larger than the expected value. On the other hand, among those aged 65 or older, those who were living alone or spouses formed larger than the expected values; those who chose "other" formed less than the expected value

relocations, $p=0.054$. Henceforth, we define "frequent relocation" as four or more relocations. Dissatisfaction with the residence was expressed by 231 people $(46.3 \%)$, and 129 people (27.9\%) planned to move to permanent housing. Risk of psychological distress was present in 161 people (33.8\%), but did not differ by age and gender groups. In addition, severe mental illness $(K 6 \geq 13)$ was present in 24 people $(4.6 \%)$.

Table 2 summarizes the association between residencerelated factors and psychological distress. Among the three residence-related factors, frequent relocation $(p=0.024)$ and dissatisfaction with the residence $(p<0.001)$ 
Table 2 Chi-square tests between residence-related factors and psychological distress

\begin{tabular}{|c|c|c|c|c|}
\hline \multirow[t]{2}{*}{ Residence-related factor } & \multirow[t]{2}{*}{ Total } & \multicolumn{2}{|l|}{ K6 } & \multirow[t]{2}{*}{$p$} \\
\hline & & $<5$ & $\geq 5$ & \\
\hline \multicolumn{5}{|l|}{ Frequent relocation } \\
\hline$<4$ & $103(22.7)$ & $78(25.8)$ & $25(16.4)$ & \multirow[t]{2}{*}{0.024} \\
\hline$\geq 4$ & $351(77.3)$ & $224(74.2)$ & $127(83.6)$ & \\
\hline \multicolumn{5}{|c|}{ Dissatisfaction with the residence } \\
\hline No & $246(54.1)$ & $186(61.4)$ & $60(39.5)$ & \multirow[t]{2}{*}{$<0.001$} \\
\hline Yes & $209(45.9)$ & $117(38.6)$ & $92(60.5)$ & \\
\hline \multicolumn{5}{|c|}{ Plan to move to permanent housing } \\
\hline No & $308(72.6)$ & $205(73.2)$ & $103(71.5)$ & \multirow[t]{2}{*}{0.712} \\
\hline Yes & $116(27.4)$ & $75(26.8)$ & $41(28.5)$ & \\
\hline
\end{tabular}

Cells show frequencies, with percentages in parentheses

were statistically significant. In contrast, plan to move to permanent housing was not significantly associated with psychological distress.

Table 3 shows the results of the multivariate logistic regression analysis, which revealed that psychological distress was significantly associated with frequent relocation (odds ratio $[\mathrm{OR}]=2.05,95 \%$ confidence interval $[\mathrm{CI}]: 1.14-3.66, p=0.016)$ and dissatisfaction with the residence $(\mathrm{OR}=2.48,95 \% \mathrm{CI}: 1.60-3.83, p<0.001)$.

Table 4 shows the results of the above analysis stratified by age and gender groups through the interaction.

With regard to gender, gender and a plan to move to permanent housing was the only statistically significant interaction noted $(p=0.011)$. After stratifying by gender, psychological distress was associated with a plan to move

Table 3 Multivariate logistic regression analysis of the association between participant characteristics and psychological distress

\begin{tabular}{llll}
\hline Variable & \multicolumn{2}{l}{ Total } & \\
\cline { 2 - 4 } & OR & $95 \% \mathrm{Cl}$ & $p$ \\
\hline Age & 1.01 & $0.99-1.03$ & 0.287 \\
Gender & 1.23 & $0.78-1.92$ & 0.373 \\
Employment status & 1.12 & $0.59-2.14$ & 0.730 \\
Financial circumstances & 0.67 & $0.37-1.21$ & 0.179 \\
Family members & 0.71 & $0.43-1.18$ & 0.187 \\
Housing damage & 0.93 & $0.83-1.04$ & 0.219 \\
Loss of close relatives & 1.21 & $0.78-1.87$ & 0.390 \\
$\begin{array}{l}\text { Frequent relocation } \\
\text { ( } \geq 4 \text { times) }\end{array}$ & 2.05 & $1.14-3.66$ & 0.016 \\
$\begin{array}{l}\text { Dissatisfaction with the } \\
\text { residence }\end{array}$ & 2.48 & $1.60-3.83$ & $<0.001$ \\
$\begin{array}{l}\text { Plan to move to permanent } \\
\text { housing }\end{array}$ & 1.32 & $0.81-2.15$ & 0.273 \\
\hline
\end{tabular}

Multivariate logistic regression was used to calculate ORs and 95\% confidence intervals $(95 \% \mathrm{Cl})$ after controlling simultaneously for independent variables. $N=418$ to permanent housing (women: $\mathrm{OR}=1.93, p=0.041$ ), and psychological distress was associated with dissatisfaction with the residence (men: $\mathrm{OR}=3.55, p=0.001$; women: $\mathrm{OR}=2.23, p=0.005)$. With regard to age group, no significant interactions were found. After stratifying by age group, psychological distress was associated with frequent relocation (younger people: $\mathrm{OR}=3.06, p=0.039$ ), dissatisfaction with the residence (younger people: $\mathrm{OR}=3.11$, $p=0.007$; older people: $\mathrm{OR}=2.43, p=0.001$ ), and a plan to move to permanent housing (younger people: $\mathrm{OR}=2.47, p=0.047)$.

\section{Discussion}

We examined the association between residence-related factors and psychological distress in evacuees after the Fukushima nuclear disaster. We found that frequent relocation and dissatisfaction with the residence were associated with psychological distress. We also found that a plan to move to permanent housing was significantly associated with psychological distress in women. In addition, the percentages of participants who scored above the cut-off points of 5 and 13 for the K6 was $33.8 \%$ and $4.6 \%$, respectively. The percentages obtained in a previous study were $28.0 \%$ and $3.0 \%$ [25], respectively. This result suggests that the participants in the present study suffer from higher psychological distress brought about by the Fukushima nuclear disaster.

The influence of relocation on psychological wellbeing appears strongly within 1 year of relocation, and then weakens over time [26]. However, in this study, there was a significant association between frequent relocation and psychological distress, even approximately 2 years and 7 months after the disaster. Previous studies have found that relocation following disasters increases the risk of psychiatric problems in evacuees [27-29]. Also, Goto [30] found that evacuees who had relocated more than two times after a disaster have an elevated risk of developing psychological problems, and concluded that the relocation itself is a primary stressor. Frequent relocation separates families and changes residential environments, increasing the possibility of psychological distress. Indeed, our study found that family size decreased after the disaster, compared to predisaster. Namely, families were forced to live separately following the Fukushima nuclear disaster, because most fathers had to remain in the disaster area due to their jobs, while their wives and children were evacuated to outside the Fukushima prefecture. Because post-disaster mental health issues that result due to the separation of family members often emerge over time, many families will seek support from mental health services [31]. In addition, frequent relocation for evacuees may have changed the social support network, because the temporary housing is located inland, far from their former 
Table 4 Stratified analysis of the adjusted association between residence-related factors and psychological distress

\begin{tabular}{|c|c|c|c|c|c|c|c|c|c|c|c|c|}
\hline \multirow[t]{2}{*}{ Variable } & \multicolumn{3}{|l|}{ Men } & \multicolumn{3}{|c|}{ Women } & \multicolumn{3}{|l|}{$<65$} & \multicolumn{3}{|l|}{$\geq 65$} \\
\hline & $\overline{\mathrm{OR}}$ & $95 \% \mathrm{Cl}$ & $p$ & $\overline{\mathrm{OR}}$ & $95 \% \mathrm{Cl}$ & $p$ & $\overline{\mathrm{OR}}$ & $95 \% \mathrm{Cl}$ & $p$ & $\overline{\mathrm{OR}}$ & $95 \% \mathrm{Cl}$ & $p$ \\
\hline Age & 1.02 & $0.99-1.06$ & 0.205 & 1.01 & $0.99-1.03$ & 0.504 & 1.056 & $1.01-1.10$ & 0.011 & 1.013 & $0.97-1.06$ & 0.541 \\
\hline Gender & N/A & N/A & N/A & N/A & N/A & N/A & 1.35 & $0.58-3.14$ & 0.484 & 1.10 & $0.62-1.96$ & 0.736 \\
\hline Employment status & 1.18 & $0.45-3.10$ & 0.744 & 1.16 & $0.48-2.85$ & 0.741 & 1.41 & $0.61-3.28$ & 0.425 & 0.92 & $0.28-2.99$ & 0.890 \\
\hline Financial circumstances & 0.52 & $0.21-1.30$ & 0.162 & 0.82 & $0.36-1.87$ & 0.634 & 0.36 & $0.14-0.93$ & 0.034 & 1.10 & $0.48-2.53$ & 0.818 \\
\hline Family members & 1.09 & $0.45-2.62$ & 0.848 & 0.63 & $0.33-1.22$ & 0.169 & 1.22 & $0.53-2.78$ & 0.643 & 0.52 & $0.25-1.05$ & 0.069 \\
\hline Housing damage & 0.99 & $0.81-1.20$ & 0.889 & 0.91 & $0.79-1.05$ & 0.206 & 0.87 & $0.71-1.07$ & 0.192 & 0.98 & $0.84-1.13$ & 0.731 \\
\hline Loss of close relatives & 1.30 & $0.60-2.83$ & 0.502 & 1.30 & $0.75-2.24$ & 0.349 & 1.57 & $0.72-3.40$ & 0.254 & 1.08 & $0.63-1.87$ & 0.779 \\
\hline Frequent relocation ( $\geq 4$ times) & 1.97 & $0.74-5.26$ & 0.174 & 1.95 & $0.93-4.11$ & 0.078 & 3.06 & $1.06-8.87$ & 0.039 & 1.79 & $0.86-3.75$ & 0.122 \\
\hline Dissatisfaction with the residence & 3.55 & $1.67-7.54$ & 0.001 & 2.23 & $1.27-3.91$ & 0.005 & 3.11 & $1.36-7.13$ & 0.007 & 2.43 & $1.41-4.19$ & 0.001 \\
\hline Plan to move to permanent housing & 0.54 & $0.22-1.33$ & 0.176 & 1.93 & $1.03-3.63$ & 0.041 & 2.47 & $1.01-6.02$ & 0.047 & 0.97 & $0.51-1.83$ & 0.918 \\
\hline
\end{tabular}

Multivariate logistic regression was used to calculate ORs and $95 \%$ confidence intervals $(95 \% \mathrm{Cl}$ ) after controlling simultaneously for independent variables. $N=418$

An interaction was noted between gender and a plan to move to move to permanent housing. No interaction was found between age and other residence-related factors 
residences [32], and neighbors in the temporary housing are not the same as before the disaster. Relocation from familiar places and people affect psychological problems [33]. Thus, frequent relocation may increase psychological distress in evacuees following the Fukushima nuclear disaster.

Our findings showed that dissatisfaction with one's residence was related to psychological distress, consistent with a previous study [15]. The majority of participants lived in privately owned houses before the disaster. Therefore, these individuals may have suffered some distress when situated in temporary housing that was smaller than their own homes before the disaster, and may have felt uncomfortable due to noise from neighbors, such as conversations and other sounds of daily life [34]. In addition, their privacy might have been compromised due to more crowded living conditions in temporary housing. Further, it is easy to imagine that the small living spaces might have led to feelings of oppression. Thus, our findings suggest that it is important to evaluate evacuees' dissatisfaction with their residences in order to understand the predictors of psychological distress for such individuals.

Evacuees might be devoid of hope for their future. A previous study found that lower levels of hope were associated with higher levels of psychological distress [35]. Therefore, we hypothesized that individuals who do not have any plan to move to permanent housing are more likely to have psychological distress. Contrary to expectations, our multivariate logistic regression analysis showed that plan to move to permanent housing was not related to psychological distress. The association might have been counterbalanced and diminished by three possible opposite relationships, which are described below. First, this indicates that plan to move to permanent housing might be a source of stress rather than hope. Indeed, the evacuees have already suffered from stress due to repeated relocation. Second, uncertainty regarding the return to their hometowns might have affected the evacuees. This may be characteristic of the evacuees of a nuclear accident. Third, the results may be explained speculatively by "reverse causality," in which individuals who had high psychological distress were more likely to have plan to move to permanent housing. Unfortunately, this study could not determine a causal relationship because of the cross-sectional study design.

In another study that was conducted among evacuees of the Great East Japan Earthquake [36], evacuees with no prospects were at higher risk of psychological distress. The reasons why these results differed from the current study are considered the following three points: 1) no evacuees of the nuclear accident were included in the sample, which likely influenced future prospects, 2) individuals that had already settled in permanent housing or were moving into new housing comprised $81 \%$ of the sample, which differed from the information obtained from evacuees in the current study (30\%), and 3) the findings of the previous study displayed a higher proportion of men and younger people than the current study. As the previous findings differed from the current results, it is necessary for future research to consider additional issues, such as residence patterns, gender, and age, and how these issues might affect plans to move to permanent housing.

In the stratified analysis, dissatisfaction with the residence was found to be associated with psychological distress, regardless of age or gender groups. While no significant interactions were found with dissatisfaction with residence in any particular group, a robust and general result was found across groups. Recent studies have directed attention toward the effects of residential environments or neighborhoods on psychological wellbeing [15]. With regard to women, psychological distress was associated with a plan to move to permanent housing. As women may have an increased sensitivity to stress hormones, their management of stress is relatively poor compared to men [37], resulting in women being considered to have an enhanced vulnerability to psychological stress. In addition, women tend to be more susceptible to disruption in social ties when compared to men [38]. For this reason, women may be more likely to feel anxious about the loss of social ties that were obtained in a small temporary housing community. Therefore, these results suggest that women who plan to move to permanent housing are prone to experience higher stress. As such, a plan to move to permanent housing was a source of potential psychological distress, rather than a hopeful future prospect for women. Thus, it is necessary to consider that plan to move to permanent housing may lead to anxiety for women.

Conversely, with regard to age group, no interactions were found to be statistically significant. After stratifying, frequent relocation and a plan to move to permanent housing were associated with psychological distress in younger people. Younger people may be more psychologically vulnerable after a disaster because they have responsibilities to society and their family, and a poor capacity for coping with such hardship [11].

The Japanese government enacted the Basic Act on Reconstruction legislation in June 2011, in response to the Great East Japan Earthquake [39]. The purpose of this Act was to promote a smooth and prompt reconstruction following the Great East Japan Earthquake. To provide a secure and stable environment for evacuees, the legislation emphasizes understanding the problems of evacuees, with a focus on the residential environment of temporary housing. Our study suggests that if a disaster evacuation is extensive, the government should provide evacuees with 
comfortable living spaces that have sufficient space, heating, and soundproofing. Such housing would reduce the risk of repeated relocation of evacuees. In addition, the government should identify high-risk individuals, such as younger people and women who are still in temporary housing 2 years after the disaster, in order to provide more effective and timely support for them.

This study has some limitations. First, there was a lag between the disaster and the interview. Since the prevalence of depression typically decreases as time passes following a disaster [40], the number of people with psychological distress was probably lower than those suffering distress immediately after the disaster. Second, our participants were residing in a particular type of temporary housing. Therefore, it is necessary to study various forms of housing, such as the rental housing provided by the Fukushima prefecture. Third, this study used a cross-sectional design, which does not allow us to draw causal conclusions. Fourth, there might have been a common method bias [41] due to the measured means, because both exposure and outcome were selfreported. Despite these limitations, the present findings provide valuable data to facilitate preparation for future major disasters. Our findings clarify the characteristics of vulnerable people, facilitating the provision of effective support. Further study is required to track longitudinal changes, and to investigate rental housing and have a larger sample of younger participants.

\section{Conclusions}

We found that concern regarding frequent relocation and dissatisfaction with the residence were associated with psychological distress among evacuees following the Fukushima nuclear disaster. Therefore, the government should provide evacuees with comfortable living spaces, and take steps to reduce the risk of repeated relocation of evacuees, so as to reduce psychological distress among this group. The stratified analysis found that plan to move to permanent housing (women) was significantly associated with psychological stress. Plan to move to permanent housing in women may adversely affect mental health rather than provide hope. Thus, women with a plan to move to permanent housing should be paid particular attention.

\section{Abbreviations}

DSM-IV: The Diagnostic and Statistical Manual of Mental Disorders, fourth edition; K6: The 6-item Kessler scale

\section{Acknowledgements}

Not applicable.

\section{Funding}

This study was supported by the Study of the Health Effects of Radiation organized by the Japanese Ministry of the Environment (PI Kawakami N); and Grant-in-Aid for Scientific Research(C) (No. 26510011).
Availability of data and material

The data will not be shared because that includes confidential personal data.

\section{Authors' contributions}

$\mathrm{NH}, \mathrm{HI}, \mathrm{NK}$, and SY designed the study, and contributed to data collection. $\mathrm{NH}, \mathrm{HI}$, and SY performed statistical analyses and wrote the draft manuscript. NK and YS contributed to scientific review. All authors discussed and interpreted the findings. All authors read and approved the final manuscript.

Competing interests

The authors declare that they have no competing financial interests.

\section{Consent for publication}

Not applicable.

\section{Ethics approval and consent to participate}

This study was approved by the ethics review committee of Fukushima Medical University (No. 1885). The study objective was explained to all participants and all were advised that 1) participation in the study was completely voluntary, 2) they could withdraw from the study at any time, and 3) if they chose to withdraw, they would not be disadvantaged in any way. Written informed consent outlining this information was obtained from each participant

\section{Author details}

${ }^{1}$ Department of Public Health, Fukushima Medical University School of Medicine, 1 Hikarigaoka, Fukushima City, Fukushima 960-1295, Japan. ${ }^{2}$ Tokyo Metropolitan Institute of Gerontology, 35-2 Sakae-cho, Itabashi-ku, Tokyo 173-0015, Japan. ${ }^{3}$ Graduate School of Medicine, The University of Tokyo, 7-3-1 Hongo, Bunkyo-ku, Tokyo 113-8654, Japan. ${ }^{4}$ National Institute of Mental Health, National Center of Neurology and Psychiatry, 4-1-1 Ogawahigashi, Kodaira, Tokyo 187-8553, Japan.

Received: 24 February 2016 Accepted: 17 November 2016

Published online: 24 November 2016

References

1. Yasumura S, Hosoya M, Yamashita S, Kamiya K, Abe M, Akashi M, et al. Study protocol for the Fukushima health management survey. J Epidemiol. 2012;22(5):375-83.

2. Yabe H, Suzuki Y, Mashiko H, Nakayama Y, Hisata M, Niwa S, et al. Psychological distress after the Great East Japan earthquake and Fukushima Daiichi Nuclear Power Plant accident: results of a mental health and lifestyle survey through the Fukushima Health Management Survey in FY2011 and FY2012. Fukushima J Med Sci. 2014;60(1):57-67.

3. Bromet EJ, Havenaar JM. Psychological and perceived health effects of the Chernobyl disaster: a 20-year review. Health Phys. 2007;93(5):516-21.

4. Fussell $E$, Lowe SR. The impact of housing displacement on the mental health of low-income parents after Hurricane Katrina. Soc Sci Med. 2014:113:137-44.

5. Norris FH, Friedman MJ, Watson PJ, Byrne CM, Diaz E, Kaniasty K. 60,000 Disaster victims speak: Part I. An empirical review of the empirical literature, 1981-2001. Psychiatry. 2002;65(3):207-39.

6. Erikson KT. Loss of communality at Buffalo Creek. Am J Psychiatr. 1976; 133(3):302-5.

7. Norris FH, Sherrieb K, Galea S. Prevalence and consequences of disaster-related illness and injury from Hurricane Ike. Rehabil Psychol. 2010;55(3):221-30.

8. Acierno R, Ruggiero KJ, Kilpatrick DG, Resnick HS, Galea S. Risk and protective factors for psychopathology among older versus younger adults after the 2004 Florida hurricanes. Am J Geriatr Psychiatry. 2006;14(12):1051-9.

9. Carr VJ, Lewin TJ, Webster RA, Kenardy JA. A synthesis of the findings from the Quake Impact Study: a two-year investigation of the psychosocial sequelae of the 1989 Newcastle earthquake. Soc Psychiatry Psychiatr Epidemiol. 1997;32(3):123-36.

10. Farfel M, DiGrande L, Brackbill R, Prann A, Cone J, Friedman S, et al. An overview of 9/11 experiences and respiratory and mental health conditions among World Trade Center Health Registry enrollees. J Urban Health. 2008:85(6):880-909.

11. Yzermans CJ, Donker GA, Kerssens JJ, Dirkzwager AJ, Soeteman RJ, Ten Veen PM. Health problems of victims before and after disaster: a longitudinal study in general practice. Int J Epidemiol. 2005;34(4):820-6. 
12. Uscher-Pines $L$. Health effects of relocation following disaster: a systematic review of the literature. Disasters. 2009;33(1):1-22.

13. Suzuki Y, Kim Y. The great east Japan earthquake in 2011; toward sustainable mental health care system. Epidemiol Psychiatr Sci. 2012;21(1):7-11.

14. Kim Y. Great East Japan earthquake and early mental-health-care response. Psychiatry Clin Neurosci. 2011;65(6):539-48.

15. Phillips DR, Siu OL, Yeh AG, Cheng KH. The impacts of dwelling conditions on older persons' psychological well-being in Hong Kong: the mediating role of residential satisfaction. Soc Sci Med. 2005;60(12):2785-97.

16. Seplaki CL, Goldman N, Weinstein M, Lin Y-H. Before and after the 1999 Chi-Chi earthquake: traumatic events and depressive symptoms in an older population. Soc Sci Med. 2006;62(12):3121-32.

17. Kun $\mathrm{P}$, Han $\mathrm{S}, \mathrm{Chen} X$, Yao L. Prevalence and risk factors for posttraumatic stress disorder: a cross-sectional study among survivors of the Wenchuan 2008 earthquake in China. Depress Anxiety. 2009;26(12):1134-40.

18. Kuwabara H, Shioiri T, Toyabe S, Kawamura T, Koizumi M, Ito-Sawamura M, et al. Factors impacting on psychological distress and recovery after the 2004 Niigata-Chuetsu earthquake, Japan: community-based study. Psychiatry Clin Neurosci. 2008;62(5):503-7.

19. Koyama S, Aida J, Kawachi I, Kondo N, Subramanian S, Ito K, et al. Social support improves mental health among the victims relocated to temporary housing following the Great East Japan Earthquake and Tsunami. Tohoku J Exp Med. 2014;234(3):241-7.

20. Montazeri A, Baradaran H, Omidvari S, Azin SA, Ebadi M, Garmaroudi G, et al. Psychological distress among Bam earthquake survivors in Iran: a population-based study. BMC Public Health. 2005;5:4.

21. Furukawa TA, Kawakami N, Saitoh M, Ono Y, Nakane $Y$, Nakamura Y, et al. The performance of the Japanese version of the K6 and K10 in the World Mental Health Survey Japan. Int J Methods Psychiatr Res. 2008;17(3):152-8.

22. Kessler RC, Andrews G, Colpe L, Hiripi E, Mroczek DK, Normand SLT, et al. Short screening scales to monitor population prevalences and trends in non-specific psychological distress. Psychol Med. 2002;32(6):959-76.

23. Sakurai K, Nishi A, Kondo K, Yanagida K, Kawakami N. Screening performance of K6/K10 and other screening instruments for mood and anxiety disorders in Japan. Psychiatry Clin Neurosci. 2011;65(5):434-41.

24. Inoue A, Kawakami N, Tsuchiya M, Sakurai K, Hashimoto H. Association of occupation, employment contract, and company size with mental health in a national representative sample of employees in Japan. J Occup Health. 2010;52(4):227-40

25. Kawakami N. National survey of mental health measured by K6 and factors affecting mental health status (in Japanese) in Research on Applied Use of Statistics and Information. Health Labour Sciences Research Grant 2006/2007.

26. Dimond M, McCance K, King K. Forced residential relocation. Its impact on the well-being of older adults. West J Nurs Res. 1987;9(4):445-64.

27. Ohta Y, Araki K, Kawasaki N, Nakane Y, Mine M, Honda S. Study on psychiatric problems of evacuees of the volcanic eruption of Mt. Unzen Factor analysis of General Health Questionnaire (GHQ-30). Japan Bulletin of Social Psychiatry. 1995;3(2):109-29. in Japanese.

28. Najarian LM, Goenjian AK, Pelcovitz D, Mandel F, Najarian B. The effect of relocation after a natural disaster. J Trauma Stress. 2001;14(3):511-26.

29. Chen YL, Lai CS, Chen WT, Hsu WY, Wu YC, Wang PW, et al. Risk factors for PTSD after Typhoon Morakot among elderly people in Taiwanese aboriginal communities. Int Psychogeriatr. 2011;23(10):1686-91.

30. Goto T, Wilson JP, Kahana B, Slane S. The Miyake Island volcano disaster in Japan: Loss, uncertainty, and relocation as predictors of PTSD and depression. J Appl Soc Psychol. 2006;36(8):2001-26.

31. Madrid PA, Grant R. Meeting mental health needs following a natural disaster: lessons from hurricane Katrina. Prof Psychol. 2008;39(1):86.

32. Nagata S, Matsunaga A, Teramoto C. Follow-up study of the general and mental health of people living in temporary housing at 10 and 20 months after the Great East Japan Earthquake. Jpn J Nurs Sci. 2015;12(2):162-5.

33. Kilic C, Aydin I, Taskintuna N, Ozcurumez G, Kurt G, Eren E, et al. Predictors of psychological distress in survivors of the 1999 earthquakes in Turkey: effects of relocation after the disaster. Acta Psychiatr Scand. 2006;114(3): 194-202.

34. Leslie $\mathrm{E}_{1}$ Cerin $\mathrm{E}$. Are perceptions of the local environment related to neighbourhood satisfaction and mental health in adults? Prev Med. 2008;47(3):273-8.

35. Glass K, Flory K, Hankin BL, Kloos B, Turecki G. Are coping strategies, social support, and hope associated with psychological distress among Hurricane Katrina survivors? J Soc Clin Psychol. 2009;28(6):779-95.
36. Nakaya N, Nakamura T, Tsuchiya N, Narita A, Tsuji I, Hozawa A, et al. Prospect of future housing and risk of psychological distress at 1 year after an earthquake disaster. Psychiatry Clin Neurosci. 2016;70(4):182-9.

37. Tang B, Liu X, Liu Y, Xue C, Zhang L. A meta-analysis of risk factors for depression in adults and children after natural disasters. BMC Public Health. 2014;14(1):623.

38. Kawachi I, Berkman LF. Social ties and mental health. J Urban Health. 2001;78(3):458-67.

39. Reconstruction Agency, Government of Japan [homepage on the Internet]. Basic Act on Reconstruction in response to the Great East Japan Earthquake. 2011 [updated 2011 June 24; cited 2015 June 02]. Available from: http://www. reconstruction.go.jp/english/topics/2012/12/basic-act.html/

40. Ohta Y, Araki K, Kawasaki N, Nakane Y, Honda S, Mine M. Psychological distress among evacuees of a volcanic eruption in Japan: a follow-up study. Psychiatry Clin Neurosci. 2003:57(1):105-11.

41. Podsakoff PM, MacKenzie SB, Lee JY, Podsakoff NP. Common method biases in behavioral research: a critical review of the literature and recommended remedies. J Appl Psychol. 2003;88(5):879-903.

\section{Submit your next manuscript to BioMed Central and we will help you at every step:}

- We accept pre-submission inquiries

- Our selector tool helps you to find the most relevant journal

- We provide round the clock customer support

- Convenient online submission

- Thorough peer review

- Inclusion in PubMed and all major indexing services

- Maximum visibility for your research

Submit your manuscript at www.biomedcentral.com/submit
) Biomed Central 